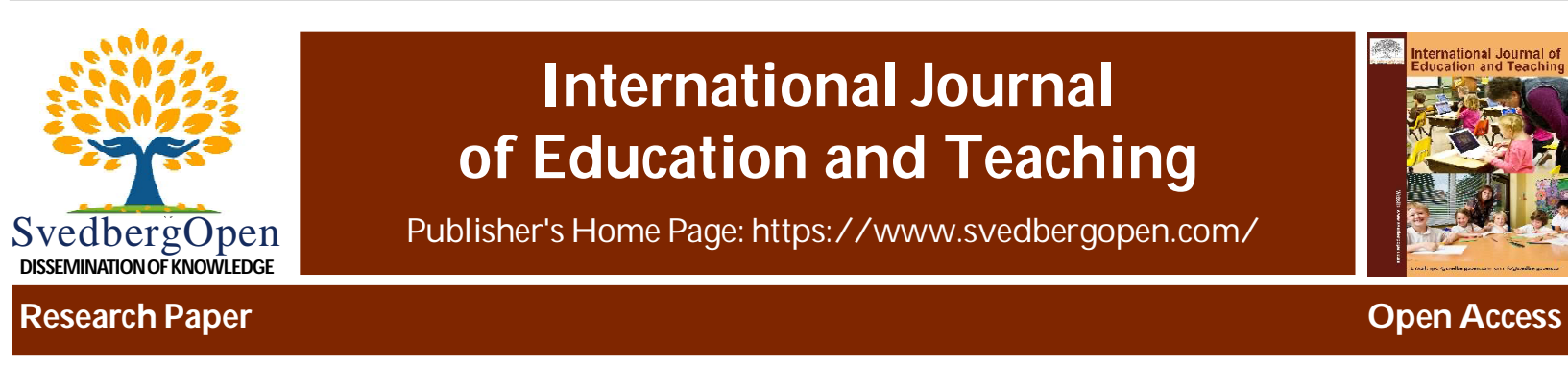

\title{
The Role of Information Technology in Education and Business
}

\section{Fatmir Halili ${ }^{*}$}

${ }^{1}$ Senior Policy Coordination Officer, Ministry of Labor and Social Welfare Department for European Integration and Policy Coordination, Square "Edit Durham" nr. 46. Prishtinë. E-mail: fatmir.halili@hotmail.com

Article Info

Volume 1, Issue 3, September 2021

Received : 20 January 2021

Accepted : 10 August 2021

Published : 05 September 2021

doi: 10.51483/IJEDT.1.3.2021.20-25

\begin{abstract}
Information technology represents the most important factor in job nowadays. In addition, information technology has become an extremely important means of communication as well as important social factor. Development of science and technology, which usually call scientific or technological progress, has always had a major impact on the overall development in all parts of society. Joint development of science and technology has brought epochal changes which are realized in different periods. Technology is always occupied in all spheres of human and especially in the sphere of material production and organization. Achievements that the condition so provocative new technology is evident today in every economy and it is quite reasonable and indeed claim that the new technology represents a decisive factor of economic development. In this paper we handle information technology in two important sectors of life in our time, namely in the XXI century, the role of information technology in business and the role of information technology in education.
\end{abstract}

Keywords: Technology, Information, Computing, Business, Education

(c) 2021 Fatmir Halili. This is an open access article under the CC BY license (https://creativecommons.org/licenses/by/4.0/), which permits unrestricted use, distribution, and reproduction in any medium, provided you give appropriate credit to the original author(s) and the source, provide a link to the Creative Commons license, and indicate if changes were made.

\section{Introduction}

Knowledge-based society need to possess good communication skills and social, to be well informed, and always be willing to learn new things. To become a member of this society, citizens should participate actively in society and feel the benefits offered by it, they should be given the opportunity to reach them and they have the knowledge and skills needed. They also need to creatively manage knowledge and experience creating original solutions to problems.

In recent times the impact of Information and Communication Technology (ICT) becomes more and more prevalent in many social spheres. This application bypasses not even education. Education and knowledge are the basis of all human development and they are the fundamental rights of every human being.

The need and purpose of the application of ICT in education is based on the fact of preparing young people to become leaders and successful in this society led by information. Communication skills, processing, critical thinking and problem solving and group work are essential in the technological society and socioeconomic XXI century. Education in this sophisticated environment will do more than just reading, writing or arithmetic skills acquisition. It should also provide job skills that will help young people reach their human potential.

\footnotetext{
* Corresponding author: Fatmir Halili, Senior Policy Coordination Officer, Ministry of Labor and Social Welfare Department for
} European Integration and Policy Coordination, Square "Edit Durham”nr. 46. Prishtinë. E-mail: fatmir.halili@hotmail.com 
When it comes to ICT in education, the device is the first thing on the agenda of policy makers. However, countries report that only investment in equipment and even how to start a policy is not good. Since the beginning, the focus should be on the uses for educational purposes ICT. It has become known that the main challenges in integrating ICT is not just computers and equipment with other, but the development of exploitation and use for educational purposes, which will effectively contribute to the achievement of the fundamental objectives of education and development needs of students ${ }^{1}$.

\section{What is Technology?}

Computers and information systems are an essential part of business in nowadays. Information technology is a modern phenomenon that has dramatically changed the daily lives of individuals and businesses worldwide.

Is the term that includes all technologies used for creating, processing, transmission, storage, exchange and use of information in all its forms, such as business records, oral conversations, photographs, paintings, video presentations and forms other, including those yet to be created. So defined, the term best integrates electronics, telecommunications computing (Informatics), the Internet and media, and can be used in the singular and plural ${ }^{2}$.

A computer network is an autonomous group of interconnected computers with the help of a certain technology. Two computers are called interconnected if they are able to exchange information between them. Connection can be accomplished by means of electric cables, optical fibers, microwave, and infrared rays or through satellites. Networks have different shapes and sizes.

\section{What is Information?}

Information (lat. information = training, education, news-rim; notice; explanation) called the news, meaning wisdom, the signs conveying system of any kind. In general, information is any news or story, any written or oral communication (spoken), is cognitive tool environment. Information is something we can learn, know or understand. In everyday language means knowledge or wisdom about a particular topic or performance. Information, in a broader definition, is the collection, processing and sequencing of a finding that increases knowledge and knowledge of the recipient. In other words, information is the circumstances in which the data is received. A precise definition of acceptable all the information there. Information is widely used concept in many areas of daily life.

\section{The Brief History of the Internet}

The Internet is presented in the eighties and nineties of the $20^{\text {th }}$ century, but the origins of its presentation are in global computer networks which are presented at the end of the sixties of the $20^{\text {th }}$ century.

Internet technology is created by Vinton Cerf in 1973 as part of a project led by Robert Kahn and organized by the Advanced Research Projects Agency, part of the U.S. Department of Defense. With this discovery, Cerf left many opportunities for creating, building and standardizing the Internet.

In 1984 the technology and networks are trusted private sector and government scientific agencies for further development. Development continued exponentially. Companies for escort services (network Providers) allowed the use of the Internet for business except for domestic purposes. In 1995, Internet access was available in 180 countries and included more than 30 million customers.

In the early nineties, before computer networks (ARPANET, BITNet, Usenet, UUCP ...) have begun to disappear, and remained in use global computer network NSFNET, which combined with a few other independent nets ${ }^{3}$. With the inclusion of more global in the NSFNET network, this network is transformed into INTERNET - international network of computers. Naming the Internet is the English abbreviation of the phrase International Network. The Internet represents a network of all computer networks, namely community of thousands of computer networks of all kinds ${ }^{4}$.

\section{Technology and Business}

Technology plays a key role in today's business environment. Many companies rely largely on computers and software to provide accurate information to effectively manage their businesses. It is becoming increasingly necessary for all

\footnotetext{
Development Report, European Commission Directorate General for Education and Culture, November 2003 , pg. 20.

www.forumi.shqiperia.com

Edmond, Beqiri. (2013). Electronic Business to Business Computing. Pea, pg. 29.

Ibid., pg. 29.
} 
businesses to include information technology solutions to operate successfully. One way that many corporations have adopted information technology on a large scale are installed Enterprise Resource Planning (ERP) systems to conduct their business and transaction processing needs of data ${ }^{5}$.

\section{Internet and Business Strategies}

Many companies have had wonderful ideas to implement on the Internet. Moreover, they even have developed business models for these ideas. Finally, due to the lack of strategy or implementing the wrong strategy, after investing millions of their capital, they have failed to implement the business models developed. So, the fascination is not part of the business and its development, but the strategy is the key element for a successful business. No doubt Porter (2011) is right when he states that the strategy is discipline, since it requires strong focus on profitability and not just on growth. Moreover it is an opportunity to define the value proposition in particular developments in the market front. Also, the strategy is willing to develop large trades by selecting what to do and what not. In this way, the basic tool to understand the impact of information technology on the company's value chain model. Because, as it highlights and Medium Enterprise (2004) each activity involves the creation, processing and communication of information, and information technology has a great impact on the value chain.

Although the Internet enables easy drive companies to market online, they must develop strategies that ensure successful penetration and stable growth in both traditional business - if companies are traditional and develop strategies for internet penetration in the market - and the market internet. For that matter, Porter (2001) estimates that the value chain should be more harmonized, consistent with the company's activities as a system that self-empowered. In this way, any competitor who attempts to imitate the strategy must replace the entire existing system instead of copying one or more characteristics of the product or the copying of one or two ways of realizing certain activities. In this view Porter (2001) even suggests "Six Principles of Strategic Positioning" (original appointment in English: "The Six Principles of Strategic Positioning") that provide for the creation and preservation of a unique strategic position.

In the early stages of technology implementation, market signals can be unreliable because new technologies catwalk pushed experimentation, as well as companies from consumers, and these experiments are often economically unsustainable. Therefore, as a result, distorted market behavior and should be interpreted with caution (Porter, 2008). For this, the implementation strategy should be based on the structure of the powers of the company to achieve electronic business which analyzes on the one hand between dimensions combining Technology Company, and people, and on the other side of the business strategy, e-business adoption and management supply chain (Ketikidis, 2006). Relying on the strategic positioning on the one hand, and on the information summarized from the study of the structure of the company's ability to realize electronic business on the other hand, can be implemented two implementation strategies: the sudden implementation strategy (known in English as all-in-one rollout strategy) and strategy implementation step-by-step (in English known as step-by-step rollout strategy) (Waser, 2011).

\section{Electronic Business}

Electronic business (e-business) is the modern form of business organization, which means intensive use of information technology, especially the Internet. It can be said that e-business today represents the most modern business methods, which tend toward all entrepreneurs for acquiring the best possible positions in trade, investment and development intensive business activity ${ }^{6}$. Among the most important reasons for which attempted to use the concept of electronic business are:

- Making the best use of all available means business, especially information.

- Trying to create the best possible position to trade, competitive position of the company respectively.

- The desire to realize the best possible results, particularly those measuring more precise financial ${ }^{7}$.

The concept of electronic business is applicable to all entrepreneurial activities. But, those in which so far have had the biggest positive results are:

- Electronic commerce

- Electronic marketing

Benjamin Bae and Paul Ashcroft (2004). Implementation of ERP Systems: Accounting and Auditing Implications. June, pg. 2. Edmond, Beqiri. (2013). Electronic Business to Business Computing. Pea, pg. 25.

Ibid., pg. 25. 
- Electronic banking service

- Computer reservation systems

However, the description of the activities in which entrepreneurship, particularly the least he can practice specific elements of electronic business and in which the Internet can serve is too long.

\section{Science and Technology}

Intensive application of computer technology in various fields of human creativity, made computers to be more present in the educational process, i.e., in the learning process. This concept promotes and changes in education, teaching contents, teaching technologies and the relationship between teachers and students. The scope of application of computers in education is virtually unlimited. There are no places where computer education cannot be used. This realization is universal system for learning, assessment of learning, to increase the quality of the work of teachers and associates, source of knowledge and learning tool more quickly and with quality. As modern technical basis of learning, the computer has an important role in its development, enrichment, aggiornamento, needs and interests of users.

To understand the impact of computer technology in education should be viewed in the essence of its application in learning. In this sense there are two main categories of computer use: learning "from" computers and learning "with" computers. When students learn "from" computers, computers are actually teachers. In this feature, computer technology in primary form serves to enlarge the knowledge and skills base. Despite this, during learning "with" computers, students use technology as a tool that can be applied for different purposes in the learning process. Students use a source that helps to develop their level of thinking, creativity, research skills, etc. Learning "from" computer, this method can be in various forms - computer-based instruction, computer assisted instruction, integrated learning systems, and intelligent systems for learning. These computers are used to teach students or 6 (software tutorial) or additional help during exercises specific skills (drill and practice software).

The fast development of information technology in libraries has impacted positively on the improvement and development of new methods, faster and more convenient to work process. The use of information technology has helped not only librarians who work their life easier, more efficient, higher quality, more attractive but also library users who have access to materials at any time in the library, in its activities, in information about her. Is behind us traditional ways of collecting and disseminating information about the materials that the library owns.

\section{Information Technology in the Enterprise}

Information technology in the enterprise is a more interactive communication sector of Small and Medium Enterprises by sensitizing them to the need for their involvement in the use and exploitation of information technology in their daily business activities, providing opportunities to integrate information technology into enterprise by opening e-mail officials in enterprise information Technology Companies enables enterprises to access official information services, promotions of their business activities, which you will create the conditions for a successful business in a profitable company and quality in their activist economic activity in the exercise of their business. Many enterprises have not open e-mails within the company which lead therefore to a rich businesses better access to information resources for their business need to make the opening-mail. Information technology, for different companies you will create the possibility of a mutual communication between each other in their businesses and businesses and government institutions. But the importance of IT and information exchange electronic mail, IT has an important role in the sale of goods. Different enterprises can make selling and buying goods online, such an opportunity comes as a result of technology development and implementation of e-Business. Electronic business is business which develops communicative mediation of information technology, especially Internet technology. Electronic business consistently generates new business models, new types of partnerships businessmen and new ways of business ${ }^{8}$.

\subsection{Business Electronic Means}

- Optimizing business processes (production, marketing, distribution, sales, payments, etc.).

- Improving relations (with the public, customer, supplier, distributor, etc.).

- Improving business services (banks, the advocacy agency, accounting, etc.).

\footnotetext{
8 www.mesazhi.com
} 
E-business is rapidly changing economy, society and politics. This is the main reason for today businesses Internet and the development of computer networks and through electronic means so much importance is given to recent years. No matter what the business is understood to develop Internet can be provided between total revenues and reduce costs. E-business or business-'s (Business angl. electronic language, or "e-business") in a broad sense can be defined as a business process which is realized with the help of automated information systems. Electronic business means that business form in which business transactions are performed primarily electronically. In general, e-business can be defined in several ways ${ }^{9}$.

\section{Technology and the Development of Human Society}

Changes accompanying the development of science and rescue techniques are quite large and full of important and right that modern information technology is a result of many achievements in the field of science and technology.

From here we can conclude that the new technology rightly called technological revolution and is recognized as the most important period of the continued development of humanity.

The discovery of the internal combustion engine is the beginning of the first industrial revolution, where machines occurs as replacement of manpower and machines also interferes with human culture and caused serious consequences for a certain period, this first game machine-one is called industrial revolution. While the beginning of this revolution is indeed associated with the detection of various machines, especially those species that replaces human labor ${ }^{10}$.

The Second Industrial Revolution also warns a revolutionary new era in the development of mankind, the era which is characterized by the replacement of many intellectual functions with those of the car, so it keeps the continuity of the development of the first revolution. Detection of reckoners' electronics, computers, transit, integrated circuits and use of diverse energy characterizes the start of today's technological revolution.

Soon it was found that the major intersections of the characters did not either-or, end of the old and entering the cloud go together and so people can understand, i.e. it is possible to organize a world society is dying, the other is arises, the French have written in their Ninth Plan.

In 80's ta late 90's and early voices still feel that we should be ready for new changes to a high-tech, except for those positive results have particularly negative consequences for the individual.

Including the third major technological revolution can best be understood if you look at all the areas in which it appears. Areas in which this revolution is appearing today are:

- Micro-electronics with its three disciplines; information technology, robotics and other forms of information.

- Biotechnology and genetic engineering,

- New sources and new forms of energy,

- New ways of using the oceans, seas or land and

- Exploitation of the universe.

Besides these major changes in different areas, new technology promotes significant changes to the economic structure, promotes the growth of labor productivity, standards, changing human needs, increase knowledge and education and socialization and humanization of working life.

Besides these major changes in large areas in various fields, new technology promotes significant changes to the economic structure, promotes the growth of labor productivity, standards, changing human needs, increasing people's knowledge and education, socialization of labor and with the conditions necessary for the emergence of socialization and humanist work and life ${ }^{11}$.

These changes are particularly in the area of production relations and behavior of people engaged in various manufacturing processes or produced, which changes not only dealing with share ownership report on capital, but also with business governance systems, ranging from those smaller wide to multinational companies.

The role of the human, which is involved in production relations, is also probably one of the most important elements that will have consequences of these changes, where the latter will be recognized only as changes in structure, but also

\footnotetext{
www.mesazhi.com

http://kohaislame.com/

http://kohaislame.com/
} 
in the processes. Where such a thing makes us think that the man at the same time it is also one that makes changes, it is also one that suffers from the changes.

Trends in development theory and technology are definitely fast, so that the dynamics of change driven by the scientific revolution-no matter epochal technological development outcomes. One of the most important indicators of these changes is the reduction of the time distance between the moment of submission of an application or technical disclosure in life or in the manufacturing process. Time required for the development of photography was 112 years (1727 to 1839) or 12 years (1922-1934) for TV and 3 years (1948-1951) for electronic integrated circuits, whereas today the development time is less than 1.5 years $^{12}$.

\section{Conclusion}

Increase speed up the rate of development of new theory and technology is the most important characteristic which shall be expressed in the contemporary world.

In research about contemporary dilemmas of humanity, is presented to the five basic elements of the global world model (population, agricultural production, productivity, consumption of natural resources and environmental pollution) are showing an exponential increase.

Trends in development theory and new technology can be represented clearly through these features:

- Disclosure of internal combustion machine and other machines,

- Systematic approach of connecting compact sites, where until recently traditionally divided into spheres of human activity,

- The distinction between physical and mental labor increasingly is losing,

- Knowledge production is becoming the main force in the fullest sense of the word and the right,

- Change the fundamental drivers of production materials, etc.

Computer industry almost precedes evolution of human history. In older times, centuries pass more quickly than new innovations designed and finding practical applications. Century 21 provides that companies reach new patents every day. Computers, but also earlier in their development today have evolved from large equipment with enormous expenditure of energy in those already working as small blocks, where records are kept and stored daily. So the difference then and now is that old computers are too big to overcome with current personal computers.

People want to be powerful, they require efficiently; delight in the speed, the ability to communicate quickly and perform some tasks in parallel with the help of electronic devices.

\section{References}

Michael, E. Porter. (2001). Strategy and the Internet, Harvard Business Review.

Ketikidis, Panayiotis, H. and Koh, Lenny. (2006). Supply Chain Management and Information Systems Handbook: Supply Chain Management and Logistics in South East Europe, South-East European Research Centre.

12 http://kohaislame.com/

Cite this article as: Fatmir Halili (2021). The Role of I nformation Technology in Education and Business. International Journal of E ducation and Teaching. 1(3), 20-25. doi: 10.51483/ IJEDT.1.3.2021.20-25. 